\title{
Methyltransferase-directed orthogonal tagging and sequencing of miRNAs and bacterial small RNAs
}

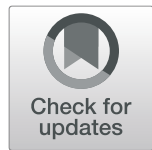

Milda Mickutè, Kotryna Kvederavičiūtè, Aleksandr Osipenko, Raminta Mineikaitė, Saulius Klimašauskaš and Giedrius Vilkaitis ${ }^{*}$ (i)

\begin{abstract}
Background: Targeted installation of designer chemical moieties on biopolymers provides an orthogonal means for their visualisation, manipulation and sequence analysis. Although high-throughput RNA sequencing is a widely used method for transcriptome analysis, certain steps, such as 3' adapter ligation in strand-specific RNA sequencing, remain challenging due to structure- and sequence-related biases introduced by RNA ligases, leading to misrepresentation of particular RNA species. Here, we remedy this limitation by adapting two RNA 2'-Omethyltransferases from the Hen1 family for orthogonal chemo-enzymatic click tethering of a $3^{\prime}$ sequencing adapter that supports cDNA production by reverse transcription of the tagged RNA.

Results: We showed that the ssRNA-specific DmHen1 and dsRNA-specific AtHEN1 can be used to efficiently append an oligonucleotide adapter to the $3^{\prime}$ end of target RNA for sequencing library preparation. Using this new chemo-enzymatic approach, we identified miRNAs and prokaryotic small non-coding sRNAs in probiotic Lactobacillus casei BL23. We found that compared to a reference conventional RNA library preparation, methyltransferase-Directed Orthogonal Tagging and RNA sequencing, mDOT-seq, avoids misdetection of unspecific highly-structured RNA species, thus providing better accuracy in identifying the groups of transcripts analysed. Our results suggest that mDOT-seq has the potential to advance analysis of eukaryotic and prokaryotic ssRNAs.

Conclusions: Our findings provide a valuable resource for studies of the RNA-centred regulatory networks in Lactobacilli and pave the way to developing novel transcriptome and epitranscriptome profiling approaches in vitro and inside living cells. As RNA methyltransferases share the structure of the AdoMet-binding domain and several specific cofactor binding features, the basic principles of our approach could be easily translated to other AdoMetdependent enzymes for the development of modification-specific RNA-seq techniques.
\end{abstract}

Keywords: Methyltransferase, RNA modification, RNA-seq, Non-coding RNA, Epitranscriptome, Probiotic

\footnotetext{
*Correspondence: saulius.klimasauskas@bti.vu.lt; giedrius.vilkaitis@bti.vu.lt Institute of Biotechnology, Life Sciences Center, Vilnius University, LT-10257 Vilnius, Lithuania

C The Author(s). 2021 Open Access This article is licensed under a Creative Commons Attribution 4.0 International License, which permits use, sharing, adaptation, distribution and reproduction in any medium or format, as long as you give appropriate credit to the original author(s) and the source, provide a link to the Creative Commons licence, and indicate if changes were made. The images or other third party material in this article are included in the article's Creative Commons licence, unless indicated otherwise in a credit line to the material. If material is not included in the article's Creative Commons licence and your intended use is not permitted by statutory regulation or exceeds the permitted use, you will need to obtain permission directly from the copyright holder. To view a copy of this licence, visit http://creativecommons.org/licenses/by/4.0/. The Creative Commons Public Domain Dedication waiver (http://creativecommons.org/publicdomain/zero/1.0/) applies to the data made available in this article, unless otherwise stated in a credit line to the data.
} 


\section{Background}

Designer chemical moieties installed in a targeted and selective manner on biopolymers can serve as orthogonal handles for their visualisation, manipulation and sequence analysis. As enzymes are the most selective and efficient catalysts known, chemo-enzymatic strategies based on repurposing transferase reactions to accept chemically modified transferrable groups are gaining an increased popularity. By far, the most widely used are $S$-adenosyl-L-methionine- (AdoMet-) dependent methyltransferases, which offer a broad range of tagging chemistries that can be deposited in vitro and in vivo [1, 2]. RNA methyltransferases are the most abundant class of RNA modifying enzymes. They incorporate a methyl group into transfer RNAs (tRNAs), ribosomal RNAs (rRNAs), messenger RNAs (mRNAs), long non-coding RNAs (lncRNAs) and various small non-coding RNAs (ncRNAs), including small nuclear RNAs (snRNAs), small nucleolar RNAs (snoRNAs), microRNAs (miRNAs) and their precursors, small interfering RNAs (siRNAs) or Piwiinteracting RNAs (piRNAs) [3]. Some of these enzymes have been successfully exploited to develop novel RNA labelling and mapping approaches [1] and techniques for identifying natural modification sites and positions $[4,5]$.

Members of the Hen1 2'-O-methyltransferase subfamily catalyse the transfer of a methyl group from $S$-adenosyl-L-methionine onto the 2'-O-ribose of the $3^{\prime}$ terminal nucleotide to protect RNA from degradation [6]. A particular Hen1 enzyme typically modifies only a definite type or a subset of RNA substrates. For example, the plant HEN1 from Arabidopsis thaliana (AtHEN1) preferentially methylates 21-24 bp long double-stranded miRNAs and siRNAs [7, 8], while the animal DmHen1 from Drosophila melanogaster is a short single-stranded piRNA and siRNA specific methyltransferase [9]. However, it has been shown that DmHen1 and especially its isolated catalytic domain DmHen $1 \Delta \mathrm{C}$ can also efficiently modify ssRNA molecules up to $80 \mathrm{nt}$ at least in vitro [10]. AtHEN1 methylation-dependent chemoselective small RNA cloning combined with next-generation sequencing has enabled the cell-type-specific miRNAs profiling in complex animal tissues even using the endogenous AdoMet cofactor [11]. Recently, Hen1 enzymes have been repurposed for the deposition of user-defined functional or reporter groups, such as fluorophore or biotin, onto the 3 ' end of the RNA strand [10, 12, 13].

In this work, we explored if such orthologous linking chemistry can be applied to advance the profiling of cellular small RNA pools. Existing RNA-seq technologies involve enzymatic ligation of sequencing adapters using RNA ligases, which are known to suffer from structure and sequence related biases leading to misrepresentation of particular RNA species [14-18]. Here, we used the DmHen1 and AtHEN1 RNA methyltransferases followed by chemical click ligation to specifically tether adapters to the 3' ends of single-stranded RNAs or doublestranded miRNAs and siRNAs, respectively. Remarkably, we found that certain reverse transcriptases were capable of faithfully producing cDNA from selected orthogonally tethered adapters. The accuracy of the newly developed methyltransferase-Directed Orthogonal Tagging and RNA sequencing (mDOT-seq) method was evaluated by using the gold standard miRXplore Universal Reference RNA. Finally, we successfully used this approach to characterise a small non-coding RNA (sRNA) transcriptome of Lactobacillus casei, which is one of the most exploited probiotic bacteria from the lactic acid bacteria (LAB) group.

\section{Results}

Hen 1 2'-O-methyltransferase-directed tagging of ssRNAs and short dsRNAs for selective cDNA production

We have previously demonstrated that AtHEN1 and an engineered version of the DmHen1 methyltransferase, DmHen $1 \Delta C$, can transfer six-carbon linear chains carrying terminal amine or azide functional groups from synthetic analogues of the $S$-adenosyl-L-methionine (AdoMet) onto the ribose of the 3 ' terminal nucleotides $[10,12,13]$. While AtHEN1 is specific for RNA duplexes of a defined length, DmHen $1 \Delta \mathrm{C}$ modifies ssRNA substrates with no apparent size limitation. To explore if these reactions can be repurposed for orthogonal covalent conjugation of sequencing adapters to the 3 ' ends of corresponding RNA species (the core steps of which are depicted in Fig. 1a), we started with a pool of synthetic randomised N21 RNA oligonucleotides containing $4.4 \times 10^{12}$ RNA sequence variants. We found that DmHEN1 $\Delta$ C-directed 3 ' terminal modification of this RNA pool using the Ado-6-azide cofactor occurred to near completion, demonstrating that the six-carbon propargylic linker with a terminal azide group can be efficiently attached to random sequences (Fig. 1b). In the next chemical ligation step, we used an alkyne-modified adapter suitable for the reverse transcription reaction. To minimise the interference of the linker in subsequent enzymatic steps, our choice fell on a copper (I)-catalysed azide-alkyne cycloaddition (CuAAC) reaction, because it produces the least bulky and least rigid cycloaddition product of defined stereochemistry (Fig. 1c illustrates a linear chain with a central triazole ring) as opposed to copper-free strain-promoted reactions which typically rely on bulky cyclooctyne derivatives (such as DBCO, $\mathrm{BCN}, \mathrm{DIFO})$ [20]. The efficiency of the click reaction was assessed using six different synthetic DNA adapters with extended alkyne moieties tethered to the $5^{\prime}$ terminal phosphate groups or to the C5 position of the first or second 5' terminal cytosine/uracil residues (Additional file 1: Fig. S1). These tethering chemistries were 


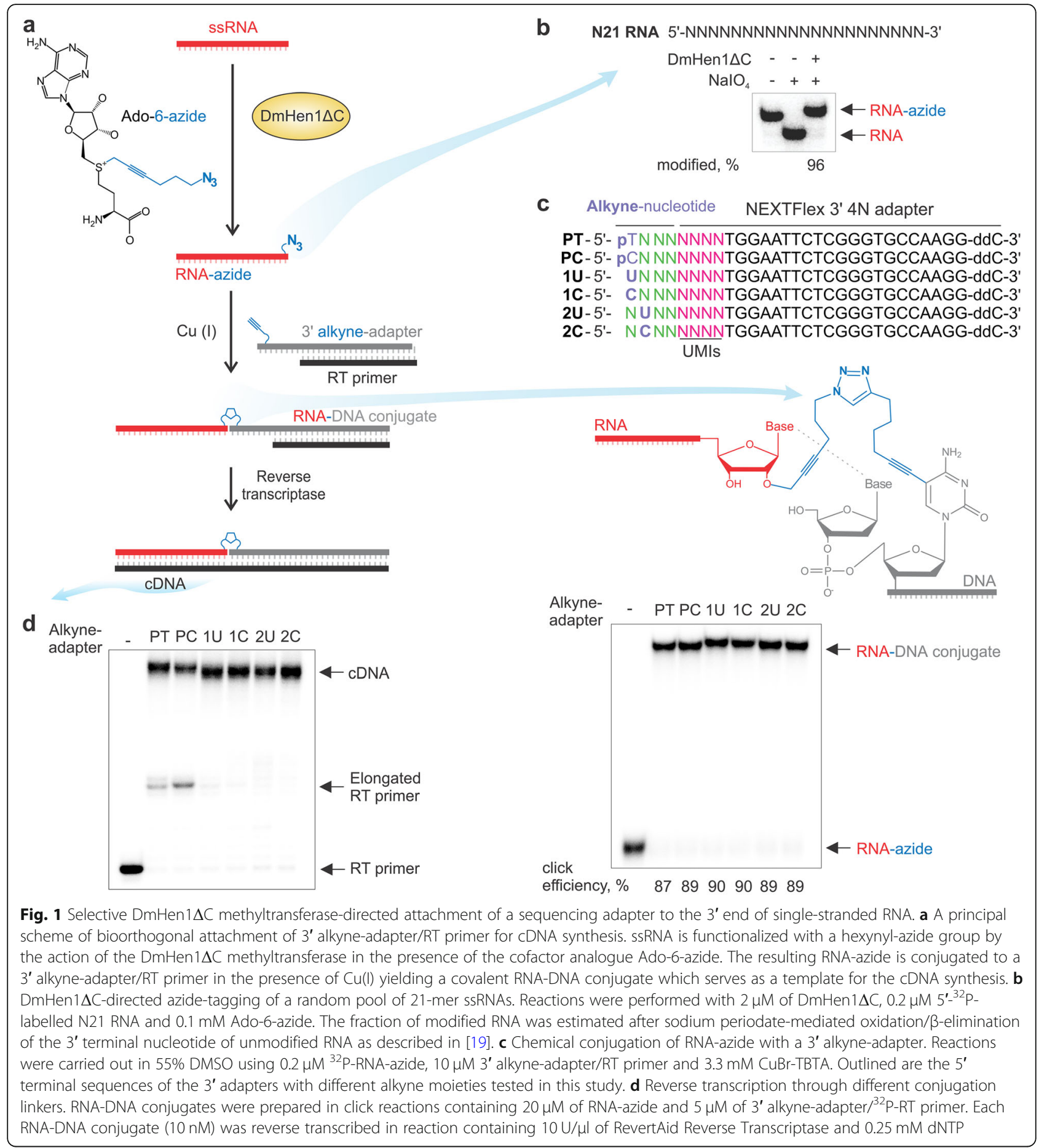

chosen based on synthetic availability and structural considerations (persistence length and conformational flexibility of the covalent tether required to promote the base stacking between the tagged 3' terminal nucleotide of the RNA strand and the $5^{\prime}$ terminal nucleotide of the attached adapter) [21]. Excellent yields of RNA-DNA conjugates were achieved with all six adapter types (Fig. 1c) even at low-nanomolar concentrations of azide- functionalised RNAs (Additional file 1: Fig. S2). Finally, the obtained six conjugates were then examined for their suitability to support the reverse transcription reaction. Remarkably, initial strand extension experiments performed with RevertAid Reverse Transcriptase showed a predominant formation of expected full-length cDNA products, as exemplified in Fig. 1d. Minor amounts of shorter cDNA fragments (where RT primer was 
extended up to covalent linker) accumulated using both RNA-DNA conjugates with alkyne-modified $5^{\prime}$ phosphate bearing adapters PT and PC indicating that this type of linker is less well tolerated by the enzyme. In contrast, no partially extended products were observed using templates with alkyne at the $\mathrm{C} 5$ position of the pyrimidine nucleobase, namely the $1 \mathrm{C}, 1 \mathrm{U}, 2 \mathrm{C}$ and $2 \mathrm{U}$ adapters. cDNA synthesis performed with M-MuLV reverse transcriptase and four of its mutants revealed high yields of the full-length product (Additional file 1: Fig. S3). However, variants lacking RNase $\mathrm{H}$ activity displayed an improved ability to traverse the orthogonal linkers. Most of the RevertAid transcripts terminating on the opposite side of the linker were appended with a short $3^{\prime}$ tail (1-3 extra nucleotides), apparently due to the stronger template-independent nucleotidyltransferase activity or protein dissociation after the synthesis of only a few nucleotides following DNA-RNA junction [22].

Analogous experiments were carried out with the AtHEN1 enzyme, which selectively modifies short double-stranded RNAs containing dinucleotide 3' overhangs, such as miRNAs and siRNAs (Fig. 2a) [23-25]. Using the Ado-6-azide cofactor, we observed efficient functionalization of both natural miRNA/miRNA* (guide/passenger strand*) duplexes and also of individual miRNA strands in heteroduplexes with addressing DNA oligonucleotide probes, miRNA/DNA (Additional file 1: Fig. S4) [13]. Similarly, the modification reaction using a mixture of four miRNA/miRNA* duplexes confirmed efficient enzymatic derivatization of all tested guide miRNAs, each containing a different 3 ' terminal nucleotide (Fig. 2b). Following the click-conjugation of the alkyneDNA adapter to the $3^{\prime}$ terminally azide-modified RNA (Fig. 2c), the miRNA template was efficiently converted into full-length cDNA via reverse transcription (Fig. 2d).

Thus, we showed that both Hen1 methyltransferases can efficiently append RNA pools with a 3' terminal azide functionality, which, in turn, can serve as an orthogonal handle for covalent tethering of a DNA adapter suitable for generating cDNA via enzymatic reverse transcription reaction.

\section{Optimization and validation of the mDOT-seq approach with a reference set of miRNAs}

To assess the capacity of the DmHEN1 $\Delta \mathrm{C}$-mediated sequencing technology, named mDOT-seq (methyltransferase-Directed Orthogonal Tagging and RNA sequencing), for high-throughput analysis of short RNAs, we exploited the gold standard miRXplore Universal Reference. This

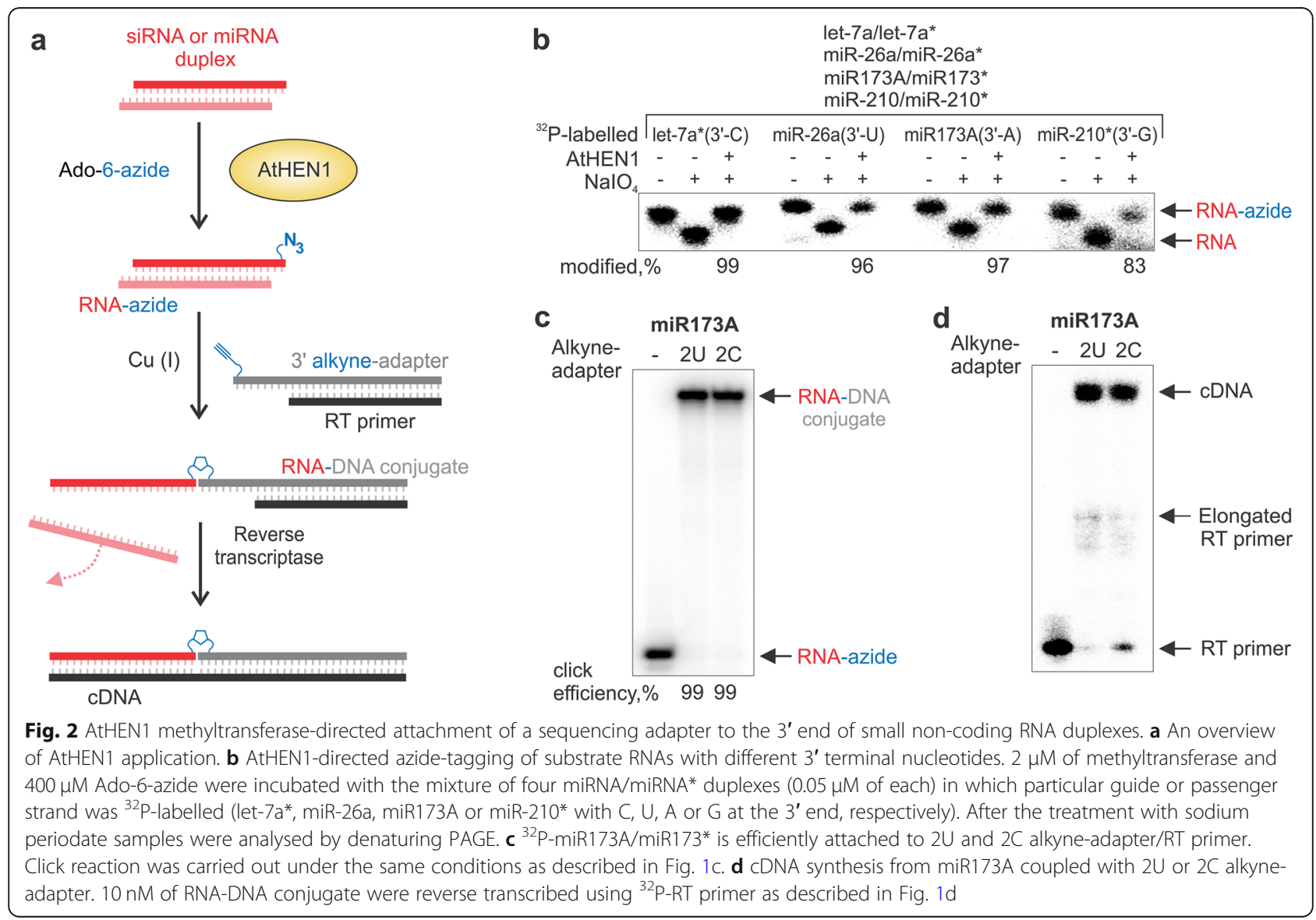


RNA pool consists of 1005 mature human, mouse, rat, and viral miRNAs ranging between 16 and $28 \mathrm{nt}$ in length, with individual oligoribonucleotides present in equimolar concentrations, which thus permits a comprehensive calibration of analytical techniques that aim at tackling the complexity of cellular miRNAome [26]. We constructed four variants of cDNA libraries employing the previously selected $1 \mathrm{C}, 1 \mathrm{U}, 2 \mathrm{C}$ and $2 \mathrm{U}$ alkyne-adapters (the NEXTflex Small RNA-seq Kit v3 protocol was applied starting from $5^{\prime}$ adapter ligation step) and subjected them to Illumina sequencing (Fig. 3a). Since experimental replicates (two sequencing libraries prepared separately for each 3' adapter) were nearly identical (Additional file 1: Fig. S5a), their reads were pooled for further analysis. Pairwise comparisons revealed the strongest correlation between the $2 \mathrm{C}$ and $2 \mathrm{U}$ libraries, indicating that moderately divergent RNA pools were captured using the $1 \mathrm{C}$ and $1 \mathrm{U} 3^{\prime}$ adapters (Additional file 1: Fig. S5b). Moreover, the $2 \mathrm{C}$ and $2 \mathrm{U}$ preparations detected slightly higher amounts of full-length miRNAs: $98.3-98.7 \%$ in $2 \mathrm{C}, 2 \mathrm{U}$ versus $97.5 \%$ in $1 \mathrm{C}$ and $1 \mathrm{U}$ libraries (Fig. $3 \mathrm{~b}$ and Additional file 1: Table S1). This difference became more apparent at higher detection thresholds (Additional file 1: Fig. S5c). Since the mapping of reads to the miRXplore sequences after trimming of $3^{\prime}$ terminal nucleotides increased the number of miRNA species identified (Fig. 3b and Additional file 1: Table S1), we suggest that the secondary structures of the $1 \mathrm{C}$ and $1 \mathrm{U} 3^{\prime}$ adapters may impact the precision of bona fide $3^{\prime}$ end calling to a greater extent than that of the $2 \mathrm{C}$ and $2 \mathrm{U} 3$ ' adapters. Also, the abundance of different RNAs in the $2 \mathrm{C}$ and $2 \mathrm{U}$ libraries showed a smaller deviation from uniformity than in the $1 \mathrm{C}$ and $1 \mathrm{U}$ libraries (Fig. 3c). Altogether, our results revealed that the 3' adapters with alkyne moieties attached to the fifth carbon atom of the second cytosine/uracil are best suited for the preparation of RNA sequencing libraries.

To understand the representation bias in the sequencing libraries, we analysed miRNAs comprising $10 \%$ of high-, medium- and low-abundant species as well as undetected ones. As shown in Additional file 1: Fig. S6, RNAs prone to forming double-stranded structures or having only short 3 ' overhangs were underrepresented in all libraries. This appears to be consistent with the requirement of a single-stranded 3' end for DmHen1 activity [10]. Other characteristics of the RNA sequences did not contribute to the RNA detection inequalities, whereas guanine-rich RNAs with higher Tm tended to be overrepresented. A detailed analysis of the preferred/ disfavoured bases at 1-16 positions upstream of the $3^{\prime}$ end revealed predisposition of detected RNAs to be repleted with $\mathrm{G}$ but depleted of $\mathrm{T}, \mathrm{A}$ and $\mathrm{C}$ nucleotides from some individual sites and lower representation of RNAs containing adenine at the $3^{\prime}$ position (Additional file 1: Fig. S7). Since the enzymatic examination revealed 3' terminal adenines as highly desirable targets for DmHen $1 \Delta C$ [10], we suggest that uneven representativeness reflects the reverse transcription or cDNA amplification biases. Thus, further optimization of the reaction conditions or selection of an RT enzyme could further reduce the inequality in the sequenced transcripts' population.

Finally, to select the optimal flanking sequences surrounding the $2 \mathrm{C}$-alkyne and $2 \mathrm{U}$-alkyne nucleotides in the 3' adapters, we calculated the transcript counts for each particular adapter sequence varying at the first, third and fourth positions (Fig. 3d). This analysis revealed a strong $\mathrm{A} / \mathrm{C}$ enrichment at the $5^{\prime}$ end but a weak nucleotide-dependence at the $3 \mathrm{rd}$ and 4 th positions (except for a disfavour for 4th A), suggesting that the sequence preference was mostly caused by the first nucleotide. Among the top-ranked adapters, DNA oligonucleotides containing ACTC and CUCC motifs at the 5' end accumulated the highest number of reads and gave the most accurate quantification of miRNAs (Fig. 3d and Additional file 1: Fig. S8) [27]. Therefore, we suggest that these sequences of 3' alkyne-adapters are optimal for effective sequencing and can be used in further experiments.

Taken together, these results show that the developed mDOT-seq procedure is capable of identifying a broad range of RNA targets and thus can be exploited for various miRNA applications. Inspired by this finding, we went on to examine the capacity of mDOT-seq for profiling of cellular single-stranded RNAs.

\section{The discovery of small non-coding RNAs in Lactobacillus casei using mDOT-seq}

To evaluate if mDOT-seq can be applied for RNA profiling in biological organisms, we went on to characterise small non-coding RNAs (sRNAs) from Lactobacillus casei strain BL23 (NCBI changed the organism's name to Lactobacillus paracasei BL23 in August 2020). It is an important model organism for understanding fundamental aspects of cell biology of lactic acids bacteria (LAB) which are widespread in the human microbiome and prominent components of probiotic compositions [2931]. Like 50-500 nt sRNAs from well-characterised bacteria [32, 33], sRNAs of LAB could potentially play essential regulatory roles in shaping different physiological processes, cellular response to biotic or abiotic stresses as well as adaptation in the gastrointestinal tract.

To obtain comprehensive profiles of sRNAs expressed at different phases of the bacterial life cycle, we pooled L. casei BL23 cells harvested at six growth points (Fig. 4a). After depletion of rRNA, the extracted RNAs were size selected (50-500 nt) and treated with RNA 5' Pyrophosphohydrolase $(\mathrm{RppH})$ to preserve the entire small transcriptome of the cell, including primary 

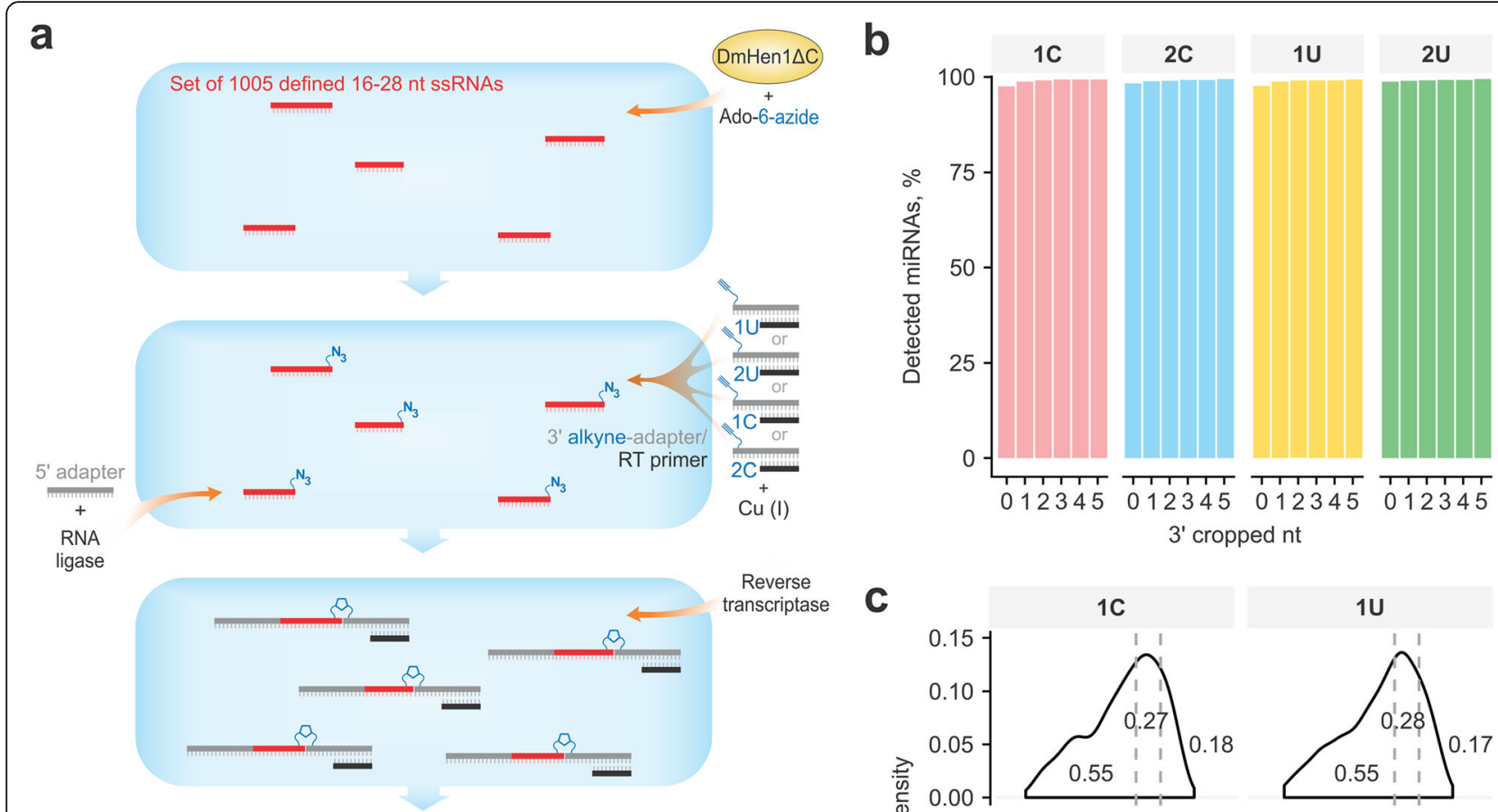

Reverse transcriptase

C

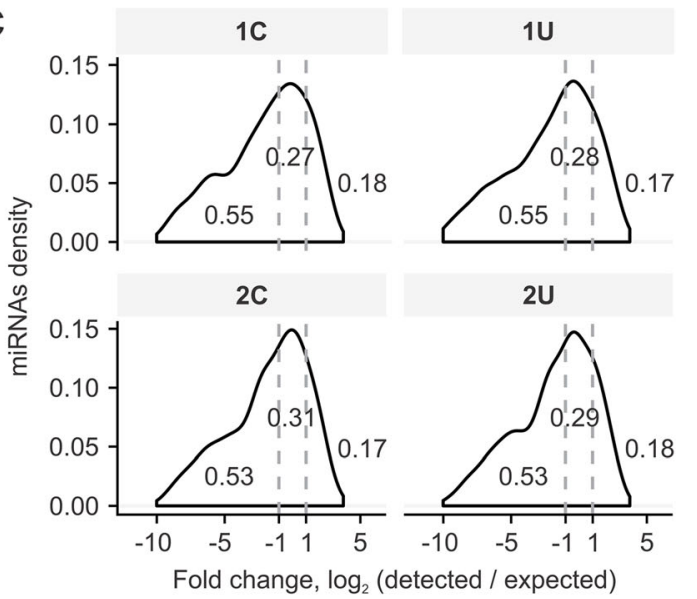

d

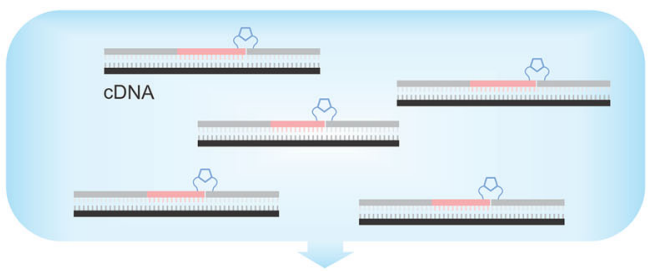

Amplification and sequencing

Fold change, $\log _{2}$ (detected / expected)
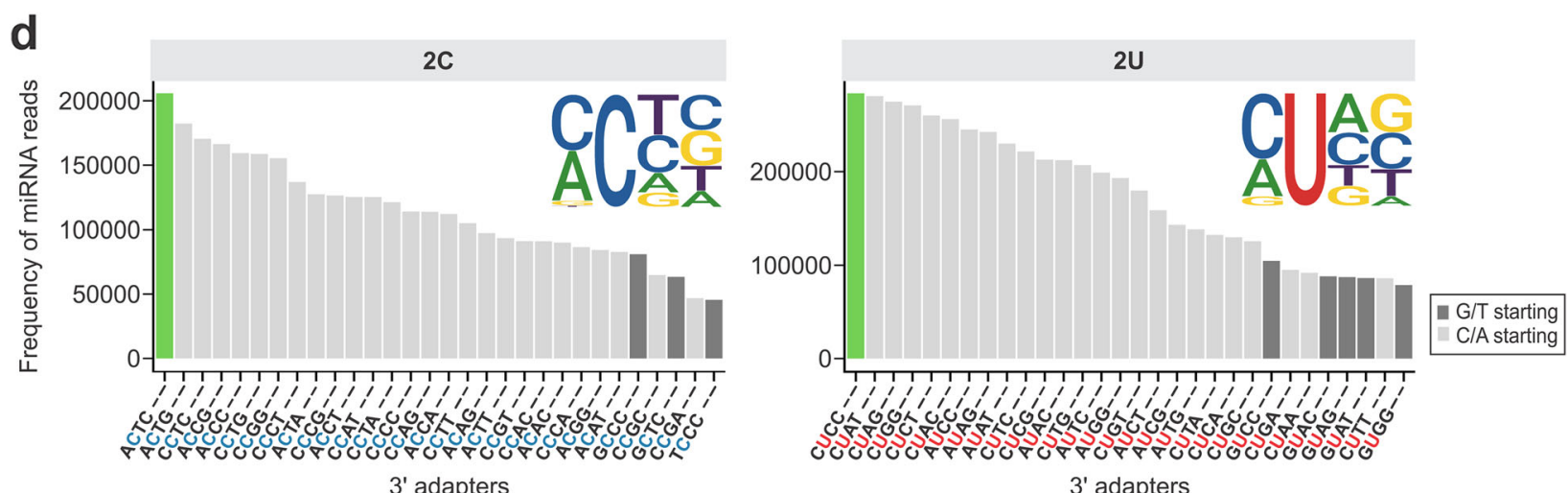

Fig. 3 Selection of alkyne-adapters through sequencing of miRXplore Universal Reference RNA libraries. a A schematic of the mDOT-seq. $\mathbf{b}$ The majority of miRNAs are detected as full-length sequences in all libraries. Bar plot shows the observed fraction of miRNAs after increasing number of nucleotides is cropped from its $3^{\prime}$ end. The exact numbers are provided in Additional file 1: Table S1. c $2 \mathrm{C}$ and $2 \mathrm{U}$ libraries contain the highest portion of accurately quantified miRNA reads. miRNAs identified in the reference set of sequences cropped of two nt at their $3^{\prime}$ end and having at least 1 CPM in each library were used to calculate fold-deviation from the equimolar input and plotted as $\log _{2}$ values. Values within two folds from the expected ones (grey vertical lines) were considered unbiased according to [27]. $\mathbf{d}$ Top 30 of $2 \mathrm{C}$ or $2 \mathrm{U} 3^{\prime}$ adapters containing different bases at first, third and fourth $5^{\prime}$ positions with the highest number of identified reads. The libraries were demultiplexed using each of $3^{\prime}$ adapters and the total number of miRNA reads was calculated. Sequence logos of top ranked adapters were created using WEBLOGO [28]. The data underlying the presented graphs are in Additional file 2 







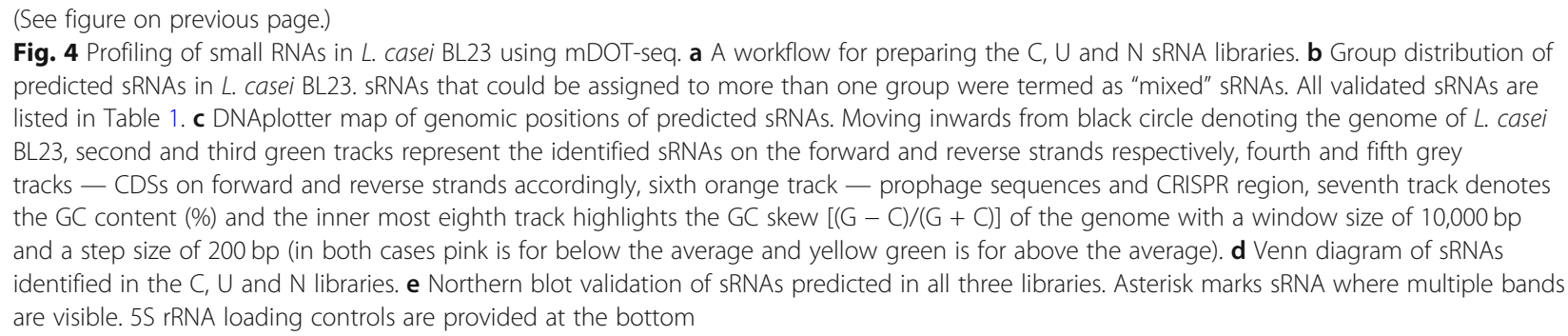

transcripts with $5^{\prime}$ triphosphates and processed RNAs containing $5^{\prime}$ monophosphates. Following the developed mDOT-seq protocol, we prepared two strand-specific sequencing libraries $\mathrm{C}$ and $\mathrm{U}$, for which 3' alkyne-adapters containing ACTC and CUCC 5' terminal sequences, respectively (Additional file 1: Fig. S9), were tethered to the pool of ssRNAs using click ligation. In parallel, a control library $\mathrm{N}$ was prepared by conventional 3' adapter ligation following NEXTflex Small RNA-seq Kit v3 protocol. After Illumina sequencing of triplicate $\mathrm{C}$, $\mathrm{U}$ and $\mathrm{N}$ libraries, we obtained an average of 15.7, 15.6 and 18.5 million high-quality paired-reads, respectively. Spearman correlation analysis of the mapped reads showed high correlations among biological replicates and the libraries, indicating a high reproducibility of the new method and its good general agreement with the conventional approach (Additional file 1: Fig. S10) [34]. A primary set of small non-coding RNAs in the transcriptome of $L$. casei was predicted by the APERO algorithm [35], which was manually processed to filter out transcripts with less than 15 average CPMs (counts per million) per library and those without distinguishable read coverage drop at their boundaries (with less than three times increase in read coverage within $2 \mathrm{nt}$ at their $5^{\prime}$ and $3^{\prime}$ ends). In total, we identified 307 putative sRNAs expressed in $L$. casei BL23 that were classified into six groups based on their genomic context (Fig. 4b$\mathrm{d}$ and Additional file 1: Fig. S11, Additional file 3: Table S2-7) as well as a group of transcripts encoded by Type II-A CRISPR-Cas system, in particular tracrRNA and some of processed crRNAs from CRISPR repeat-spacer array. The putative sRNAs included 86 intergenic, 107 untranslated region- (UTR-) derived, 65 antisense and 12 intragenic small RNAs, as well as 37 mixed sRNAs that could be assigned to more than one group, which is consistent with a number of non-coding RNAs generally observed in other bacteria [36]. Unlike protein-encoding genes ( $72 \%$ coding sequences, CDSs, are located on the leading strands in both directions from the replication origin of L. casei circular chromosome), intergenic sRNAs (56\%) as well as sRNAs of all types (60\%) exhibit weaker coding strand bias (Fig. 4c). Because genes encoded on the lagging strand are mutated more frequently [37], an increased mutagenesis rate is likely less deleterious for sRNAs and/or potentially beneficial for the adaptation to the environmental changes.

Out of 307 putative small non-coding RNAs in L. casei genome, 235, 226 and 257 were identified in $\mathrm{C}$, $\mathrm{U}$ and $\mathrm{N}$ RNA sequencing data, respectively (Fig. 4d). A comprehensive comparison of short transcripts revealed that most $5^{\prime}$ end boundaries were reliably detected in all samples (Additional file 1: Fig. S12a). The libraries prepared by different techniques showed higher transcript heterogeneity at the 3' ends (Additional file 1: Fig. S12b). Still, we consider that this bias is not inherent to a particular library preparation method because similar levels of 1-2 nt shorter transcripts were assigned in all libraries. 186 sRNAs were shared between all three libraries, and 201 overlapped when the $\mathrm{N}$ library prepared by the conventional method was compared to the libraries prepared by mDOT-seq (the sum of $\mathrm{C}$ and $\mathrm{U}$ ), whereas 56 and 50 sRNAs were only predicted in the $\mathrm{N}$ and $\mathrm{C}+$ $\mathrm{U}$ sequencing libraries, respectively (Fig. $4 \mathrm{~d}$ ). We found that $\mathrm{C}+\mathrm{U}$ exhibited only a few more putative intergenic (6 versus 4 ), antisense (16 vs 7), and 5' UTR-derived sRNAs (12 vs 7) as compared to N. 3' UTR-derived sRNA candidates were the most divergent: we detected 22 unique transcripts in $\mathrm{N}$ library prepared by the conventional method and only 7 in $\mathrm{C}+\mathrm{U}$ libraries (Additional file 1: Fig. S13a). Moreover, all fifteen mixed group sRNAs found only in the $\mathrm{N}$ dataset could be attributed to 3' UTR-derived sRNAs (6 in $\mathrm{C}+\mathrm{U})$. Thus, conventional RNA-seq tends to over-assign 3' UTRderived sRNAs. The logistic regression analysis of unique sRNAs revealed that candidates identified only in the $\mathrm{N}$ library are predisposed to form more stable secondary structures (of lower minimum free energy, $p<0.05$ ) and contain shorter unstructured $3^{\prime}$ ends $(p<0.001)$ as compared to sRNAs identified only in the $\mathrm{C}+\mathrm{U}$ libraries (Additional file 3: Table S8).

The cellular expression of selected sRNA candidates was experimentally verified by Northern blotting (Fig. 4e). The analysis of transcripts observed in all three libraries supports the sequencing data. All 23 tested 
sRNAs covering five different groups according to the genome context showed clearly detectable signals (Table 1 and Additional file 1: Fig. S14). In contrast, only 3 out of 8 candidate sRNAs predicted exclusively in the $\mathrm{N}$ library at the 3' UTR were validated by Northern blotting (Table 1 and Additional file 1: Fig. S13b-d). This result implies that most of the unique 3' UTR-derived sRNAs can be falsely predicted using conventional RNA sequencing. Thus, compared to the conventional library preparation protocol, the mDOT-seq method takes advantage of slightly better accuracy in detecting this group of transcripts. Overall, our experiments demonstrated the potential of the mDOT-seq technique as a powerful tool for small RNA analysis that is likely to become a viable alternative to the conventional RNA sequencing based on T4 RNA ligase 2 and hampered by its sequence and structure related biases [14-18].

To understand the functions of predicted sRNAs, we searched the RNA families database (Rfam) [38, 39]. Although most candidates showed no similarity to the known RNA families suggesting their novelty, we could define the functions of 17 sRNAs. Three of them matched the housekeeping RNAs, including the catalytic RNA of RNase P (sLCB1642-), transfer-messenger

Table 1 Candidate sRNAs analysed by Northern blotting (NB)

\begin{tabular}{|c|c|c|c|}
\hline & Group & Name & Verified by NB \\
\hline \multirow[t]{23}{*}{ sRNAs predicted in all libraries } & Intergenic & SLCB577.2- & + \\
\hline & & sLCB761- & + \\
\hline & & sLCB1299+ & + \\
\hline & & sLCB1806- & + \\
\hline & & sLCB2150- & + \\
\hline & & sLCB2545+ & + \\
\hline & & sLCB2784+ & + \\
\hline & & sLCB2938+ & + \\
\hline & Antisense & sLCB561+ & + \\
\hline & & sLCB568- & + \\
\hline & & sLCB2773+ & + \\
\hline & & sLCB2785+ & + \\
\hline & & sLCB3035- & + \\
\hline & 5' UTR-derived & sLCB724+ & + \\
\hline & & sLCB922+ & + \\
\hline & & sLCB1856- & + \\
\hline & & sLCB2097+ & + \\
\hline & 3' UTR-derived & sLCB266.5+ & + \\
\hline & & sLCB1674- & + \\
\hline & & sLCB2321- & + \\
\hline & & sLCB3076- & + \\
\hline & Mixed - 3' UTR-derived/5' UTR-derived & sLCB1312+ & + \\
\hline & Mixed - 3' UTR-derived/antisense & sLCB2083+ & + \\
\hline \multirow[t]{10}{*}{ sRNAs predicted only in the $N$ library } & Intergenic & sLCB1735- & + \\
\hline & 5' UTR-derived & sLCB616+ & + \\
\hline & 3' UTR-derived & sLCB3+ & - \\
\hline & & sLCB518- & - \\
\hline & & sLCB1192- & - \\
\hline & & sLCB1398+ & + \\
\hline & & sLCB1968- & + \\
\hline & & sLCB2960- & + \\
\hline & Mixed - 3' UTR-derived/antisense & sLCB1933- & - \\
\hline & & sLCB2710+ & - \\
\hline
\end{tabular}


RNR, tmRNA (sLCB1161-), and a signal recognition particle RNA (sLCB2400-). Other 14 predicted sRNAs belonged to nine RNA families of cis-regulatory elements (Additional file 3: Table S2). In addition, 2 sRNAs showed significant similarity to families of Enterococcus sRNAs (sLCB266.5+ and sLCB2938-). To evaluate the extent of taxonomical conservation of predicted sRNAs, we performed a blast search against six genomes from Lactobacillus casei group (LCG) of closely related bacteria [40] and nine genomes from more evolutionarily distant species of Lactobacillaceae family (Additional file 3: Table S9). As expected, the highest fraction of homologous sequences was identified in LCG, especially in the genomes of $L$. paracase $i$ LcA (DN-11401, branded as defensis) and L. paracasei LcY (Shirota) isolated from Actimel and Yakult products marketed as probiotics, respectively [41]. All of the predicted sRNAs were present in $L$. paracasei LcA strain and showed sequence identity of more than $99 \%$ except for one sRNA (88.9\%). Similar results were obtained in the search against $L$. paracasei LcY genome: only two sRNAs had sequence identity lower than $99 \%$, and no similar sequences were identified for eight sRNAs (the incomplete assembly of L. paracasei LcY genome could account for the missing sRNAs). The obtained results confirm a close relatedness of these three strains indicating that the sRNA sequencing data generated in this study could potentially be translated to these broadly used probiotics. Homologues of sRNAs were also identified in $L$. paracasei ATCC (for 246 species), L. paracasei subsp. paracasei 8700:2 (242), L. rhamnosus GG (81) and L. casei DSM $20011=$ JCM 1134 = ATCC 393 (76). In contrast, we could only detect sequences similar to 9 predicted sRNAs (including two housekeeping) in other tested strains of Lactobacillaceae family. Not a single homologue was identified in the genomes of Lactobacillus acidophilus NCFM and Liquorilactobacillus nagelii strain TMW 1.1827. Taken together, the obtained results indicate that the majority of sRNAs in L. casei BL23 are strictly group-specific.

\section{Discussion}

\section{mDOT-seq as a new approach for RNA sequencing}

In the current work, we show that a bioorthogonal chemo-enzymatic approach using small RNA methyltransferases can be successfully applied for covalent tethering of a suitable DNA adapter selectively to the 3' end of target RNA permitting efficient RT reaction and strand-specific RNA-seq library preparation. Most importantly, with both DmHen1 $\Delta C$ and AtHEN1, different RNA substrates are modified and later joined to the 3' adapters in a sequence independent manner (Figs. 1b, c, $2 \mathrm{~b}, \mathrm{c})$. This comes in contrast to the conventional RNAseq library preparation when accurate identification of the $3^{\prime}$ terminal sequences is desirable. As several studies have shown, the inefficient primer ligation by T4 RNA ligase 2 stands out as the main reason of the often observed RNA sequence bias [14-18]. It has been reported that the conventional ligation reaction is prone to enriching or depleting certain RNAs from the sequencing library based on their secondary structure, number of unpaired nucleotides at the $3^{\prime}$ end or RNA-adapter co-fold $[14,18,42]$. The reported observations go in line with our results, showing that putative $L$. casei sRNAs detected only in the $\mathrm{N}$ library prepared using T4 RNA ligase 2 are more structured and have fewer free nucleotides at the 3' end as compared to sRNAs identified only in the $\mathrm{C}$ and $\mathrm{T}$ libraries prepared by $\mathrm{mDOT}$-seq (Additional file 3: Table S8). Interestingly, the detected falsepositives in the $\mathrm{N}$ library are enriched in 3' UTRs (Additional file 1: Fig. S13).

Installation of an orthogonal covalent linker bridging the target RNA with a sequencing adapter inevitably poses a question of how well it can be tolerated by available RT enzymes. We were surprised to learn that most of the RT variants were rather efficient in bypassing the examined DNA-RNA linker variants (Additional file 1: Fig. S3). Our systemic selection of the most efficient and accurate 3' alkyne-adapter chemistries found that attachment of the linker chain at the second nucleotide supports efficient bypass synthesis of cDNA (Figs. 1d, 2d) permitting the lowest bias in miRNA quantification (Fig. 3c, Additional file 1: Fig. S8) [27]. A similar basic linker design has been successfully used for non-homologous tag-directed internal priming of the DNA polymerase action [21, 43], suggesting that similar underlying principles may govern the strand extension reactions on both RNA (A-helix) and DNA (B-helix) templates by distinct polymerase/transcriptase enzymes. This proposed structural feature of the priming reaction is a proper positioning of the 3' terminal nucleotide of the template strand aided by the following major factors: the flexible chemical linker, stacking interactions with the $5^{\prime}$ terminal nucleotide of the tethered adapter [21] and, possibly, interaction with certain residues in the catalytic site of the RT. In addition, we found that the identity of the first nucleotide at the $5^{\prime}$ end of the adapter appears to play some role as nucleobases possessing an exocyclic amino group in the major groove $(\mathrm{C}$ and $\mathrm{A})$ resulted in the highest number of reads identified (Fig. 3d). The structural basis of this phenomenon is not clear.

As the results obtained with the selected $2 \mathrm{C}$ and $2 \mathrm{U}$ adapters are highly similar with respect to both the reproducibility (Additional file 1: Fig. S10) [34] and the breadth of sRNA capture (Fig. 4d), we believe that either adapter or their combination can well be used for analytical applications. On the other hand, since a suboptimal, $\mathrm{M}-\mathrm{MuLV}$, reverse transcriptase was used in the 
miRXplore Universal Reference sequencing experiment, the observed sRNA capture bias (Additional file 1: Fig. S6, S7) possibly stems from this particular step in the RNA library preparation. It is therefore likely that this minor bias can be reduced or even eliminated by selection of better-performing reverse transcription enzyme and further refinement of the procedure.

\section{mDOT-seq profiling of sRNAs in probiotic Lactobacillus casei}

Starting from the miRXplore Universal Reference and expanding to the sRNA transcriptome of L. casei BL23 we prove that $\mathrm{mDOT}$-seq can be used for the identification and quantitation of RNAs ranging from $16 \mathrm{nt}$ to at least $500 \mathrm{nt}$ in length. To the best of our knowledge, this is the first thorough characterisation of a L. casei BL23 sRNA transcriptome, as up to date only one report has described sRNAs in the Lactobacillus genus [44]. In total, we identify 307 putative sRNAs with more than a third deriving from $5^{\prime}$-UTR, 3 '-UTR and intragenic loci (Fig. 4b). This finding goes in line with the increasing recognition of the prevalence of small transcripts from the aforementioned regions [36, 45, 46].

As more than a fifth of the predicted sRNAs are conserved among the analysed representative strains of Lactobacillus casei group (LCG) (Additional file 3: Table S9), we envision that the results obtained in this study will serve as a valuable resource for achieving a better understanding of LCG physiology or even their improved applications in industry and medicine. LCG are among the most studied probiotics with high potential in prophylactics and therapeutics. Administration of LCG improves the balance of gut microbiota and has a positive effect on the brain function, weight management in obese patients and control of infectious and autoimmune diseases, including cancer. As probiotics LCG encounters numerous stressors both before administration and in gastrointestinal tract and respond to them by subtle alterations in their metabolism [40, 47]. The importance of sRNAs in stress response pathways are well appreciated in broadly characterised enterobacteria [48]. The produced data will serve as a useful source and prime the elucidation of the roles of sRNAs in stress response in LCG bacteria.

RNA methyltransferases are increasingly applied for analysis of both transcriptome and epitranscriptome [4, $5,11,49]$. We envision that mDOT-seq can be instrumental for detecting transcriptomic profiles of total ssRNAs (with DmHen1) and 21-24 dsRNAs (with AtHEN1) in situ or for analysing the methylome of piRNAs (using DmHen1) and miRNA/siRNA duplexes (with AtHEN1) in vivo. In this context, mDOT-seq would bring the advantage of direct identification of modifiable nucleotide in live cells. From a broader perspective, we suggest that the general methyltransferase-tagged RNA sequencing approach, successfully exemplified here using Hen1 methyltransferases, could adapt other RNA methyltransferases for transcriptome wide identification and profiling of their modification sites at a single-base resolution.

\section{Conclusions}

Progress in innovative bioorthogonal ligation methodologies provides a plethora of opportunities for advanced biomolecular analysis in vitro, in live cells and in whole organisms. Here, we exploited two $S$-adenosyl-L-methionine dependent RNA methyltransferases for the development of a new chemo-enzymatic approach methyltransferase-Directed Orthogonal Tagging and RNA sequencing, mDOT-seq - as an attractive alternative to conventional T4 RNA ligase-based RNA-seq library preparation which suffers from RNA sequence and structure related biases. The dsRNA specific AtHEN1 and ssRNA modifying DmHen1 were applied for sequence independent transfer of a six-carbon linear chain carrying a terminal azide group from a synthetic AdoMet analogue onto the 3' terminal RNA nucleotide for subsequently adapter-tagging using copper-catalysed azide-alkyne cycloaddition. We demonstrate that the resulting RNA-DNA linkage with a central triazole ring can be efficiently traversed by certain reverse transcriptases during the synthesis of cDNA. To our knowledge, this is the first application of a bioorthogonal click reaction mediated 3' adapter ligation for RNA-seq library preparation. mDOT-seq was successfully applied for the identification of 16-28 nt miRNAs and 50-500 nt small non-coding bacterial sRNAs thus resulting in the characterisation of the sRNA profile of the probiotic Lactobacillus casei BL23. We envision that the presented mDOT-seq technique could be easily adapted to a wide variety of other RNA methyltransferases or could be expanded to facilitate the analysis of (epi)transcriptome not only in vitro but also in living cells.

\section{Methods \\ ssRNA modification using DmHen $1 \Delta \mathrm{C}$, click reaction and reverse transcription}

DmHen $1 \Delta C$ was expressed and purified as described in Mickutè et al. [10]. All alkylated DNA oligonucleotides were purchased from Base Click while RT primer and N21 RNA was ordered from Metabion. Where needed nucleic acids were labelled at the $5^{\prime}$ end using ATP, $\left[\gamma^{-}{ }^{32} \mathrm{P}\right]$ (PerkinElmer) and T4 PNK (Thermo Fisher Scientific) following the manufacturer's recommendations. For RNA modification with azide group, $0.2-10 \mu \mathrm{M}$ of N21 RNA (random sequence 21-mer) was mixed with $0.1-0.2 \mathrm{mM}$ Ado-6-azide and $2 \mu \mathrm{M}$ of DmHen $1 \Delta \mathrm{C}$ in the ssRNA modification reaction buffer containing 10 
$\mathrm{mM} \mathrm{Co}{ }^{2+}$ in the form of $\mathrm{CoCl}_{2}$ salt, $10 \mathrm{mM}$ Tris- $\mathrm{HCl}$ (pH 7.4), $50 \mathrm{mM} \mathrm{NaCl}, 5 \%$ glycerol, $0.2 \mathrm{mM}$ DTT, 0.1 $\mathrm{mg} / \mathrm{ml} \mathrm{BSA}$ and $0.04 \mathrm{U} / \mu \mathrm{l}$ RiboLock RNase inhibitor (Thermo Fisher Scientific) and incubated for 30-60 min at $37^{\circ} \mathrm{C}$. Reactions were quenched with Proteinase $\mathrm{K}$ as described in Mickute et al. [10], and RNA was precipitated after the addition of $1 / 10$ volume of $3 \mathrm{M} \mathrm{NaOAc}$, pH 5.2:20 mg/ml glycogen (19:1) and 2.5 volumes of $96 \%$ ethanol and dissolved in water. Click reactions were performed in 55\% DMSO containing 0.025-0.2 $\mu$ M RNAazide, $1.25-10 \mu \mathrm{M}$ 3' alkyne-adapter/RT primer (5'GCCTTGGCACCCGAGAATTCCA-3') (annealed at equimolar amount in Annealing buffer of 7.5 mM HEPE S- $\left.\mathrm{KOH}, 0.5 \mathrm{mM} \mathrm{MgCl}_{2}, 25 \mathrm{mM} \mathrm{KCl}, \mathrm{pH} 7.4\right)$ and 3.3 $\mathrm{mM}$ of freshly prepared $\mathrm{CuBr}$-TBTA for $30 \mathrm{~min}$ at $45^{\circ} \mathrm{C}$. As for reverse transcription, the concentrations of reagents in click reaction were modified so that $20 \mu \mathrm{M}$ of RNA-azide was mixed with $5 \mu \mathrm{M}$ of $3^{\prime}$ alkyne-adapter/ RT primer and incubated for $45 \mathrm{~min}$. Following precipitation, $10 \mathrm{nM}$ of RNA-DNA conjugate was reverse transcribed in provided reaction buffer containing $1 \mathrm{U} / \mu \mathrm{l}$ RiboLock RNase inhibitor, $0.25 \mathrm{mM}$ of dNTP and $10 \mathrm{U} /$ $\mu \mathrm{l}$ of RevertAid, RevertAid H Minus, Maxima or Maxima H Minus Reverse Transcriptase (Thermo Fisher Scientific) at $38^{\circ} \mathrm{C}$ or $\mathrm{M}-\mathrm{MuLV}$ Reverse Transcriptase (New England Biolabs) at $42^{\circ} \mathrm{C}$ for $2-4 \mathrm{~h}$. The reaction was terminated by heating at $70^{\circ} \mathrm{C}$ for $10 \mathrm{~min}$. All samples were analysed on $13 \%$ denaturing polyacrylamide gel (dPAG) as described in Mickutė et al. [10].

\section{dsRNA modification using AtHEN1, click reaction and reverse transcription}

AtHEN1 was expressed and purified as described in Osipenko et al. [13]. All alkylated DNA oligonucleotides were purchased from Base Click, while RT primer, miRNAs and non-alkylated DNAs were ordered from Metabion (Additional file 4: Table S10). Where needed nucleic acids were labelled at the $5^{\prime}$ end using ATP, $\left[\gamma^{-}{ }^{32} \mathrm{P}\right]$, and annealed to a complimentary strand by incubating at $85^{\circ} \mathrm{C}$ for $3 \mathrm{~min}$ with subsequent cool down by $-0.6^{\circ} \mathrm{C} / \mathrm{min}$ to $4{ }^{\circ} \mathrm{C}$ resulting in RNA/RNA or RNA/ DNA duplexes with 2 nt $3^{\prime}$ overhangs. For RNA modification with azide group $0.2-10 \mu \mathrm{M}$ of miRNA/miRNA* or miRNA/DNA substrate(-s) was mixed with 0.3$400 \mu \mathrm{M}$ Ado-6-azide and $0.25-2 \mu \mathrm{M}$ of AtHEN1 in the dsRNA modification reaction buffer $(10 \mathrm{mM}$ Tris- $\mathrm{HCl}$, $\mathrm{pH} 7.5,50 \mathrm{mM} \mathrm{NaCl}, 0.1 \mathrm{mg} / \mathrm{ml}$ BSA and $0.04 \mathrm{U} / \mu \mathrm{l}$ RiboLock RNase inhibitor (Thermo Fisher Scientific)) and incubated for $1-2 \mathrm{~h}$ at $37^{\circ} \mathrm{C}$. Reactions were quenched with Proteinase $\mathrm{K}$ and RNA was precipitated as described above. Click reactions, reverse transcription and analysis on dPAG were performed as described earlier.
miRXplore Universal Reference RNA library preparation $2.5 \mu \mathrm{M}$ of miRXplore Universal Reference (Miltenyi Biotec) RNA was heated to $82.5^{\circ} \mathrm{C}$ in the presence of 0.1 $\mathrm{mM}$ EDTA for $2 \mathrm{~min}$ and immediately placed on ice for $5 \mathrm{~min}$. Then, RNA sample was split in two and libraries were prepared in duplicate for each 3 ' alkyne-adapter. $2 \mu \mathrm{M}$ of DmHen $1 \Delta \mathrm{C}$ was used to modify $0.2 \mu \mathrm{M}$ of miRXplore RNA in the ssRNA modification reaction buffer as described earlier. Proteinase $\mathrm{K}$ treatment and RNA precipitation was followed by click reaction during which $0.4 \mu \mathrm{M}$ of RNA-azide was incubated with $10 \mu \mathrm{M}$ of $3^{\prime}$ alkyne-adapter/RT primer and precipitated afterwards. 0.35 pmol of RNA-DNA conjugate was used for RNA library preparation according to the NEXTflex Small RNA-seq Kit v3 (PerkinElmer) starting from Step $\mathrm{B}$ with the following modifications: at Step D, 1/4 dilution of NEXTflex 5' $4 \mathrm{~N}$ adapter was used; at Step G, 18 cycles of PCR were performed; and Step H1 was proceeded with Step H2. The size distribution of the library was evaluated by capillary electrophoresis on the Agilent 2100 Bioanalyzer using Agilent High Sensitivity DNA Kit (Agilent Technologies) and quantified via a qPCR reaction using KAPA Library Quantification Kit (Roche) on a Rotor-Gene Q instrument. All RNA libraries were pooled and sequenced at Lexogen facilities using NextSeq 500/550 High Output Kit to obtain $1 \times 75$ nt singleend reads.

\section{miRXplore Universal Reference sequencing data analysis}

The quality of raw sequencing reads was evaluated using FASTQC program (https://www.bioinformatics. babraham.ac.uk/projects/fastqc/). Reads that were too short (less than 10 bases), had no adapters or contained $\mathrm{Ns}$ in the sequence were removed from further analysis using cutadapt [50]. Remaining reads were deduplicated using custom Unix script and size filtered to fit a range of 15 to $34 \mathrm{nt}$. To count the reads corresponding to each miRNA, we created custom reference libraries from 1005 distinct miRNAs by extracting only those that differed by their $\mathrm{n}-\mathrm{x}$ nucleotides from the $5^{\prime}$ end (where $\mathrm{n}$ is equal to the length of the miRNA and $x$ denotes the number of nucleotides cropped from its $3^{\prime}$ end, $0 \leq \mathrm{n} \leq$ 5). These reference libraries and a custom Unix script was used to calculate the amount of individual miRNA in each sample by exact match. All statistical calculations were performed using R 3.5 [51].

Data analysis pipeline is provided in the following scheme.

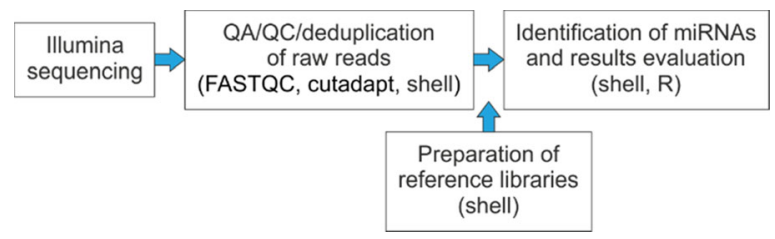




\section{L. casei sRNR library preparation}

Lactobacillus casei BL23 (a kind gift of Marie-Pierre Chapot-Chartier and Saulius Kulakauskas from Micalis Institute, INRA, France) was grown in $200 \mathrm{ml}$ of $\mathrm{BD}^{\text {тм }}$ Difco $^{\mathrm{Tm}}$ Lactobacilli MRS Broth at $37^{\circ} \mathrm{C}$ until it reached six different growth points in early, mid and late exponential and stationary growth phases where equal amount of bacteria were collected from three biological replicates, mixed with $1 / 8$ volume of ice-cold STOP solution (95\% ethanol and 5\% acid phenol), centrifuged and stored at $-80^{\circ} \mathrm{C}$. Frozen cells from all six growth stages were mixed and ground to a fine powder in liquid nitrogen. About $100 \mathrm{mg}$ of ground powder was used for the total RNA extraction with RNAzol RT (RN 190) (Molecular Research Center, Inc.) according to the manufacturer's recommendations. The quality of extracted RNA was evaluated using Agilent RNA 6000 Nano Kit (Agilent Technologies). For sRNA library preparation total RNA was treated with DNase I, RNase free (Thermo Scientific) following the manufacturer's recommendations and recovered from the reaction using RNA Clean \& Concentrator-25 Kit (Zymo Research). rRNAs were depleted using the modified RiboMinus Transcriptome Isolation Kit, bacteria (Invitrogen) where $2 \mu \mathrm{l}$ of RiboMinus Probes and $2 \mu \mathrm{l}$ of $100 \mu \mathrm{M}$ mix of three probes specific to $5 \mathrm{~S}$ rRNA were used (Additional file 4: Table S11). After ethanol precipitation RNA was subjected to size selection as 50-500 nt RNA was cut out of $8 \%$ denaturing PAA gel. Gel slices were crushed with a disposable pestle and RNA was eluted in $500 \mu \mathrm{l}$ of Elution buffer $\left(0.5 \mathrm{M} \mathrm{NH}_{4} \mathrm{OAc}, 0.1 \%\right.$ SDS, $0.1 \mathrm{mM}$ EDTA) in $4 \mathrm{~h}$ in a $25^{\circ} \mathrm{C}$ incubator rotating at $300 \mathrm{rpm}$. The eluate was collected using Corning Costar Spin-X Centrifuge Tube Filters (Merck) and RNA precipitated with 1/ 10 volume of $3 \mathrm{M} \mathrm{NaOAc}$, pH $5.2: 20 \mathrm{mg} / \mathrm{ml}$ glycogen (19:1) and 2.5 volumes of $96 \%$ ethanol. After treatment with RNA 5' Pyrophosphohydrolase (RppH) (New England Biolabs) according to the manufacturer's recommendations and further recovery with RNA Clean \& Concentrator-5 Kit (Zymo Research) for mDOT-seq $1.6 \mu \mathrm{M}$ of RNA was heated at $82.5^{\circ} \mathrm{C}$ for $2 \mathrm{~min}$ in the presence of $0.1 \mathrm{mM}$ of EDTA and immediately transferred on ice for $5 \mathrm{~min}$. As with miRXplore Universal Reference library preparation, $0.2-0.3 \mu \mathrm{M}$ of RNA were modified with azide group and $0.2 \mu \mathrm{M}$ of azide-RNA was used for click reaction. Two picomoles of RNA-DNA conjugate was further processed according to the NEXTflex Small RNA-Seq Kit v3 (PerkinElmer) starting from the Step B with couple modifications listed: at Step D, 1/4 dilution of NEXTflex 5' $4 \mathrm{~N}$ adapter was used; at Step E, incubation at $42{ }^{\circ} \mathrm{C}$ was extended to $60 \mathrm{~min}$; at Step G, 15 PCR cycles were performed; and Steps F and H1 were carried out as described in alternative protocol for Preparing Libraries without Size Selection. For N libraries, 2 pmol of
$\mathrm{RppH}$ treated RNA was processed according to the NEXTflex Small RNA-Seq Kit v3 (PerkinElmer) with modifications in Steps E, F and H1 identical to mDOTseq protocol except for Step G were only 12 PCR cycles were performed. The quality and concentration of libraries was evaluated as indicated above. All libraries were pooled and sequenced at Lexogen facilities using NextSeq 500/ 550 Mid Output Kit to obtain $2 \times 75$ paired-end reads.

\section{L. casei sRNA sequencing data analysis}

The quality of raw sequencing reads was evaluated using FASTQC program v0.11.9 (https://www.bioinformatics. babraham.ac.uk/projects/fastqc/). Low-quality reads or those having Ns were filtered out using cutadapt v2.9 [50], and data was deduplicated using BBTools package v38.41 (https://sourceforge.net/projects/bbmap/). Deduplicated dataset was quality (PHRED threshold 20) and length (minimum length 30) filtered using Trim Galore! v0.6.5 (https://www.bioinformatics.babraham.ac.uk/ projects/trim_galore/). Adaptor sequences were removed using UMI tools v1.0.1 [52]. Resulting reads were mapped using hisat2 v2.2.0 [53] on a L. casei reference genome (NC_010999.1). Mapped data were subjected to APERO v1.0.3 [35] analysis (using standard parameters except for the wmax $=3$ and min_read_number $=10$ ) and followed by a manual crosscheck. Transcripts of $>$ $3 \mathrm{x}$ increase in read coverage within $2 \mathrm{nt}$ at their $5^{\prime}$ and 3 ' ends in at least one of three replicates were considered as potential sRNAs. In cases where based on the required increase in read coverage slightly different coordinates were assigned to the same sRNA in separate libraries, for the common list of sRNAs, the widest ones were picked. Abundance of predicted sRNAs was evaluated using featureCounts from RSubread v1.32.4 package [54] and normalised using TMM method (edgeR v3.24.3 package) [55]. Only sRNAs with an average CPM of $\geq$ 15 in at least one library were included in further analysis. Promoters and terminators of candidate sRNAs were predicted using BPROM and FindTerm [56] using standard search parameters. sRNAs homologue sequences in other genomes were identified and aligned using standalone BLAST 2.9.0+ [57] and needle from EMBOSS package v6.6.0.0 [58] using standard search and alignment parameters. RFAM families were identified using Infernal cmscan at EBI (https://www.ebi.ac. uk/Tools/rna/infernal_cmscan/) [59]. sRNAs' structures and minimal free energies were calculated using RNAfold program from Vienna RNA package v2.4.16 [60]. Visual genomic representations of potential sRNAs were created using Integrative Genomic Viewer [61]. Custom Unix script was used to prepare the data and artificially fill in insert and concatenate paired end reads. All statistical calculations were performed using $\mathrm{R} 3.5$ [51], 
except for logistic regression analysis which was done using past3 software [62].

Pipeline for sequencing data analysis and identification of putative sRNAs is provided in the following scheme.



\section{Northern blot analysis}

To validate predicted sRNAs, $10 \mu \mathrm{g}$ of total RNA was fractionated on an $8 \%$ polyacrylamide/ $7 \mathrm{M}$ urea gel and transferred to SensiBlot ${ }^{\mathrm{m}}$ Plus Nylon Membrane (Thermo Scientific) by electroblotting at $5 \mathrm{~V}$ for $2 \mathrm{~h}$ using $V 20-S D B$ semi-dry blotter (Fisherbrand). Blots were UV-cross-linked by irradiation at $254 \mathrm{~nm}, 25 \mathrm{~J}$ in a crosslinker (UVITEC Cambridge) and prehybridised for $2 \mathrm{~h}$ with a Hybridization buffer $\left(0.5 \mathrm{M} \mathrm{Na}_{2} \mathrm{HPO}_{4} \times\right.$ $2 \mathrm{H}_{2} \mathrm{O}, 7 \%$ SDS, $1 \mathrm{mM}$ EDTA, $1 \%$ (w/v) BSA, pH 7.2). Membranes were incubated overnight at $42{ }^{\circ} \mathrm{C}$ with $\gamma^{32}$ P-ATP end-labelled oligodeoxyribonucleotides specific to certain sRNAs (Additional file 4: Table S12). Hybridised blots were washed three times in a Wash buffer $1(2 \times$ SSC, $0.1 \%$ SDS $), 2(1 \times$ SSC, $0.1 \%$ SDS $)$ and $3(0.1 \times \mathrm{SSC} / 0.1 \% \mathrm{SDS})$ for $15 \mathrm{~min}$ at $42^{\circ} \mathrm{C}$ and exposed to phosphor imaging plates (Fujifilm). Signals were visualised with a FLA-5100 Image Reader (Fujifilm). The same membranes were used to detect $5 \mathrm{~S}$ rRNA after stripping of radiolabelled probe with boiling $0.1 \%$ SDS twice. Stripped blots were washed 3 times with water and hybridised with $5 \mathrm{~S}$ rRNA probe as described above.

\section{Supplementary Information}

The online version contains supplementary material available at https://doi. org/10.1186/s12915-021-01053-w.

Additional file 1: Fig. S1. The chemical structures of alkyne-modified nucleotides and nucleosides. Fig. S2. Alkyne-adapter is efficiently attached to RNA-azide of nanomolar concentration. Fig. S3. CDNA synthesis through a conjugation linker using different reverse transcriptases. Fig. S4. Different miRNAs are efficiently modified using Ado-6-azide cofactor and AtHEN1. Fig. S5. Comparison of libraries prepared using different 3' alkyne-adapters. Fig. S6. Effects of various factors on miRNA representation in mDOT-seq libraries. Fig. S7. Deviation of observed nucleotides frequencies from expected values in 3'-terminal section (16 positions) of identified miRNAs. Fig. S8. Evaluation of the miRNA quantification accuracy using different $3^{\prime}$ alkyne-adapters. Fig. S9. Sequence of 3' alkyne-adapters applied for Lactobacillus casei sRNAs sequencing. Fig. S10. Spearman correlation among biological replicates of the L. casei libraries. Fig. S11. Classification of sRNAs into groups based on their genomic context. Fig. S12. The amount of predicted sRNAs with shorter $5^{\prime}$ or $3^{\prime}$ ends is similar among different libraries. Fig. S13. Putative
3' UTR-derived sRNAs tend to be incorrectly identified in the N library. Fig. S14. Read coverage plots of experimentally verified sRNAs identified in all three libraries. Table S1. The number of miRNA species captured in sequenced libraries.

Additional file 2. The data underlying published graphs.

Additional file 3: Table S2. List of predicted SRNAs and their main features. Table S3. List of predicted sRNAs originating from more than one loci and their main features. Table S4. Promoters of predicted sRNAs. Table S5. Terminators of predicted sRNAs. Table S6. Detailed genomic context of predicted sRNAs. Table S7. Detailed genomic context of predicted sRNAs originating from more than one loci. Table S8. Structural characteristics of predicted sRNAs. Table S9. Conservation of predicted sRNAs in Lactobacillaceae family.

Additional file 4: Table S10. The list of RNA and DNA oligonucleotides used for labelling of double-stranded substrates with AtHEN1. Table S11. The list of $L$. casei BL23 $5 S$ rRNA specific probes used for rRNA depletion. Table S12. DNA oligonucleotides used for Northern blot analysis.

\section{Acknowledgements}

The authors thank Marie-Pierre Chapot-Chartier and Saulius Kulakauskas (Université Paris-Saclay, INRAE, AgroParisTech, Micalis Institute, France) for a kind gift of the L. casei BL23 strain, Viktoras Masevičius (Department of Organic Chemistry, Faculty of Chemistry and Geosciences, Vilnius University, Lithuania) for a kind gift of the Ado-6-azide cofactor and Alexandra Plotnikova for comments and helpful discussions.

\section{Authors' contributions}

M.M., S.K. and G.V. conceived this project. M.M. performed the DmHen1 analysis. A.O. performed the AtHEN1 analysis. M.M. prepared the sequencing libraries. K.K. performed the bioinformatics analysis. R.M. performed the Northern blot analysis. M.M. and G.V. performed the formal analysis and prepared original draft. S.K. edited the manuscript. All authors read and approved the final manuscript.

\section{Authors' information}

Milda Mickutè - Twitter: @MildaMickute

Raminta Mineikaitè - Twitter: @RMineikaite

\section{Funding}

This work was supported by the Research Council of Lithuania [MIP-19-31 to G.V.] and the European Research Council [ERC-AdG-2016/742654 to S.K.].

\section{Availability of data and materials}

All data generated or analysed during this study are included in the published article, its supplementary information files and publicly available repositories. RNA-seq data generated for this study are deposited on GEO under accession GSE166932.

\section{Declarations}

Ethics approval and consent to participate Not applicable

\section{Consent for publication}

Not applicable

\section{Competing interests}

M.M., G.V. and S.K. are inventors named on a patent related to the analysis of single-stranded RNA.

Received: 23 February 2021 Accepted: 24 May 2021

Published online: 22 June 2021

\section{References}

1. Tomkuvienè M, Mickutè M, Vilkaitis G, Klimašauskas S. Repurposing enzymatic transferase reactions for targeted labeling and analysis of DNA and RNA. Curr Opin Biotechnol. 2019;55:114-23. https://doi.org/10.1016/j. copbio.2018.09.008. 
2. Deen J, Vranken C, Leen V, Neely RK, Janssen KPF, Hofkens J. Methyltransferase-directed labeling of biomolecules and its applications. Angew Chem Int Ed Eng. 2017;56(19):5182-200. https://doi.org/10.1002/a nie.201608625.

3. Shi H, Wei J, He C. Where, when, and how: context-dependent functions of RNA methylation writers, readers, and erasers. Mol Cell. 2019;74(4):640-50. https://doi.org/10.1016/j.molcel.2019.04.025.

4. Hartstock K, Nilges BS, Ovcharenko A, Cornelissen NV, Püllen N, LawrenceDörner A-M, et al. Enzymatic or in vivo installation of propargyl groups in combination with click chemistry for the enrichment and detection of methyltransferase target sites in RNA. Angew Chem Int Ed. 2018;57(21): 6342-6. https://doi.org/10.1002/anie.201800188.

5. Shu X, Dai $Q$, Wu T, Bothwell IR, Yue Y, Zhang Z, et al. N6-Allyladenosine: A new small molecule for RNA labeling identified by mutation assay. J Am Chem Soc. 2017;139(48):17213-6. https://doi.org/10.1021/jacs.7b06837.

6. Huang $\mathrm{RH}$. Unique 2'-O-methylation by Hen1 in eukaryotic RNA interference and bacterial RNA repair. Biochemistry. 2012;51(20):4087-95. https://doi. org/10.1021/bi300497x

7. Vilkaitis G, Plotnikova A, Klimasauskas S. Kinetic and functional analysis of the small RNA methyltransferase HEN1: the catalytic domain is essential for preferential modification of duplex RNA. RNA. 2010;16(10):1935-42. https:// doi.org/10.1261/rna.2281410.

8. Yang Z, Ebright YW, Yu B, Chen X. HEN1 recognizes 21-24 nt small RNA duplexes and deposits a methyl group onto the $2^{\prime} \mathrm{OH}$ of the $3^{\prime}$ terminal nucleotide. Nucleic Acids Res. 2006;34(2):667-75. https://doi.org/10.1093/na r/gkj474.

9. Saito K, Sakaguchi Y, Suzuki T, Suzuki T, Siomi H, Siomi MC. Pimet, the Drosophila homolog of HEN1, mediates 2'-O-methylation of Piwiinteracting RNAs at their 3' ends. Genes Dev. 2007;21(13):1603-8. https://doi. org/10.1101/gad.1563607.

10. Mickute M, Nainyte $M$, Vasiliauskaite L, Plotnikova A, Masevicius V, Klimašauskas S, et al. Animal Hen1 2'-O-methyltransferases as tools for 3'terminal functionalization and labelling of single-stranded RNAs. Nucleic Acids Res. 2018;46(17):e104. https://doi.org/10.1093/nar/gky514.

11. Alberti C, Manzenreither RA, Sowemimo I, Burkard TR, Wang J, Mahofsky K, et al. Cell-type specific sequencing of microRNAs from complex animal tissues. Nat Methods. 2018;15(4):283-9. https://doi.org/10.1038/nmeth.4610.

12. Plotnikova A, Osipenko A, Masevičius V, Vilkaitis G, Klimašauskas S. Selective covalent labeling of miRNA and siRNA duplexes using HEN1 methyltransferase. J Am Chem Soc. 2014;136(39):13550-3. https://doi.org/1 0.1021/ja507390s.

13. Osipenko A, Plotnikova A, Nainytè M, Masevičius V, Klimašauskas S, Vilkaitis G. Oligonucleotide-addressed covalent 3'-terminal derivatization of small RNA strands for enrichment and visualization. Angew Chem Int Ed Eng. 2017:56(23):6507-10. https://doi.org/10.1002/anie.201701448.

14. Hafner M, Renwick N, Brown M, Mihailović A, Holoch D, Lin C, et al. RNAligase-dependent biases in miRNA representation in deep-sequenced small RNA cDNA libraries. RNA N Y N. 2011;17(9):1697-712. https://doi.org/10.12 61/rna.2799511.

15. Jayaprakash $A D$, Jabado $O$, Brown BD, Sachidanandam R. Identification and remediation of biases in the activity of RNA ligases in small-RNA deep sequencing. Nucleic Acids Res. 2011;39(21):e141. https://doi.org/10.1093/nar/ gkr693.

16. Sorefan K, Pais H, Hall AE, Kozomara A, Griffiths-Jones S, Moulton V, et al. Reducing ligation bias of small RNAs in libraries for next generation sequencing. Silence. 2012;3(1):4. https://doi.org/10.1186/1758-907X-3-4.

17. Zhang Z, Lee JE, Riemondy K, Anderson EM, Yi R. High-efficiency RNA cloning enables accurate quantification of miRNA expression by deep sequencing. Genome Biol. 2013;14(10):R109. https://doi.org/10.1186/gb-2 013-14-10-r109.

18. Zhuang F, Fuchs RT, Sun Z, Zheng Y, Robb GB. Structural bias in T4 RNA ligase-mediated 3'-adapter ligation. Nucleic Acids Res. 2012;40(7):e54. https://doi.org/10.1093/nar/gkr1263.

19. Yang Z, Vilkaitis G, Yu B, Klimasauskas S, Chen X. Approaches for studying microRNA and small interfering RNA methylation in vitro and in vivo. Methods Enzymol. 2007:427:139-54. https://doi.org/10.1016/S0076-6879(07)27008-9.

20. George JT, Srivatsan SG. Posttranscriptional chemical labeling of RNA by using bioorthogonal chemistry. Methods San Diego Calif. 2017;120:28-38. https://doi.org/10.1016/j.ymeth.2017.02.004.

21. Gibas P, Narmontè M, Staševskij Z, Gordevičius J, Klimašauskas S, Kriukienè E. Precise genomic mapping of 5-hydroxymethylcytosine via covalent tether- directed sequencing. PLoS Biol. 2020;18(4):e3000684. https://doi.org/10.13 71/journal.pbio.3000684.

22. Zajac $P$, Islam S, Hochgerner H, Lönnerberg P, Linnarsson S. Base preferences in non-templated nucleotide incorporation by MMLV-derived reverse transcriptases. PLoS ONE. 2013;8(12):e85270. https://doi.org/10.1371/ journal.pone.0085270.

23. Yu B, Yang Z, Li J, Minakhina S, Yang M, Padgett RW, et al. Methylation as a crucial step in plant microRNA biogenesis. Science. 2005;307(5711):932-5. https://doi.org/10.1126/science.1107130.

24. Plotnikova A, Baranauskè S, Osipenko A, Klimašauskas S, Vilkaitis G. Mechanistic insights into small RNA recognition and modification by the HEN1 methyltransferase. Biochem J. 2013;453(2):281-90. https://doi.org/10.1 042/BJ20121699.

25. Baranauskè S, Mickutè M, Plotnikova A, Finke A, Venclovas Č, Klimašauskas S, et al. Functional mapping of the plant small RNA methyltransferase: HEN1 physically interacts with HYL1 and DICER-LIKE 1 proteins. Nucleic Acids Res. 2015:43(5):2802-12. https://doi.org/10.1093/nar/gkv102.

26. Baroin-Tourancheau A, Jaszczyszyn Y, Benigni X, Amar L. Evaluating and correcting inherent bias of microRNA expression in Illumina sequencing analysis. Front Mol Biosci. 2019;6. https://doi.org/10.3389/fmolb.2019.00017.

27. Fuchs RT, Sun Z, Zhuang F, Robb GB. Bias in ligation-based small RNA sequencing library construction is determined by adaptor and RNA structure. PLoS One. 2015;10(5):e0126049. https://doi.org/10.1371/journal. pone.0126049.

28. Wagih O. ggseglogo: a versatile $R$ package for drawing sequence logos. Bioinformatics. 2017;33(22):3645-7. https://doi.org/10.1093/bioinformatics/btx469.

29. Mazé A, Boël G, Zúñiga M, Bourand A, Loux V, Yebra MJ, et al. Complete genome sequence of the probiotic Lactobacillus casei strain BL23. J Bacteriol. 2010;192(10):2647-8. https://doi.org/10.1128/JB.00076-10.

30. Jacouton E, Chain F, Sokol H, Langella P, Bermúdez-Humarán LG. Probiotic strain Lactobacillus casei BL23 Prevents colitis-associated colorectal cancer. Front Immunol. 2017;8. https://doi.org/10.3389/fimmu.2017.01553.

31. De Filippis F, Pasolli E, Ercolini D. The food-gut axis: lactic acid bacteria and their link to food, the gut microbiome and human health. FEMS Microbiol Rev. 2020;44(4):454-89. https://doi.org/10.1093/femsre/fuaa015.

32. Diallo I, Provost P. RNA-sequencing analyses of small bacterial RNAs and their emergence as virulence factors in host-pathogen interactions. Int J Mol Sci. 2020;21(5). https://doi.org/10.3390/ijms21051627.

33. Hör J, Matera G, Vogel J, Gottesman S, Storz G. Trans-acting small RNAs and their effects on gene expression in Escherichia coli and Salmonella enterica. EcoSal Plus. 2020;9(1). https://doi.org/10.1128/ecosalplus.ESP-0030-2019.

34. Robinson MD, McCarthy DJ, Smyth GK. edgeR: a Bioconductor package for differential expression analysis of digital gene expression data. Bioinformatics. 2010;26(1):139-40. https:/doi.org/10.1093/bioinformatics/btp616.

35. Leonard S, Meyer S, Lacour S, Nasser W, Hommais F, Reverchon S. APERO: a genome-wide approach for identifying bacterial small RNAs from RNA-Seq data. Nucleic Acids Res. 2019:47(15):e88. https://doi.org/10.1093/nar/gkz485.

36. Adams PP, Storz G. Prevalence of small base-pairing RNAs derived from diverse genomic loci. Biochim Biophys Acta Gene Regul Mech. 2020;1863(7): 194524. https://doi.org/10.1016/j.bbagrm.2020.194524.

37. Schroeder JW, Sankar TS, Wang JD, Simmons LA. The roles of replicationtranscription conflict in mutagenesis and evolution of genome organization. PLoS Genet. 2020;16(8):e1008987. https:/doi.org/10.1371/journal.pgen.1008987.

38. Kalvari I, Argasinska J, Quinones-Olvera N, Nawrocki EP, Rivas E, Eddy SR, et al. Rfam 13.0: shifting to a genome-centric resource for non-coding RNA families. Nucleic Acids Res. 2018;46(D1):D335-42. https://doi.org/10.1093/nar/gkx1038.

39. Kalvari I, Nawrocki EP, Argasinska J, Quinones-Olvera N, Finn RD, Bateman A et al. Non-coding RNA analysis using the Rfam database. Curr Protoc Bioinformatics. 2018;62(1):e51. https://doi.org/10.1002/cpbi.51.

40. Hill D, Sugrue I, Tobin C, Hill C, Stanton C, Ross RP. The Lactobacillus casei group: history and health related applications. Front Microbiol. 2018;9:2107. https://doi.org/10.3389/fmicb.2018.02107.

41. Douillard FP, Kant R, Ritari J, Paulin L, Palva A, de Vos WM. Comparative genome analysis of Lactobacillus casei strains isolated from Actimel and Yakult products reveals marked similarities and points to a common origin. Microb Biotechnol. 2013;6(5):576-87. https://doi.org/10.1111/1751-7915.12062.

42. Jackson TJ, Spriggs RV, Burgoyne NJ, Jones C, Willis AE. Evaluating biasreducing protocols for RNA sequencing library preparation. BMC Genomics. 2014;15(1):569. https://doi.org/10.1186/1471-2164-15-569.

43. Staševskij Z, Gibas P, Gordevičius J, Kriukiene E, Klimašauskas S. Tethered oligonucleotide-primed sequencing, TOP-Seq: a high-resolution economical 
approach for DNA epigenome profiling. Mol Cell. 2017;65:554-564.e6. https://doi.org/10.1016/..molcel.2016.12.012.

44. Nakashima Y, Shiiyama N, Urabe T, Yamashita H, Yasuda S, Igoshi K, et al. Functions of small RNAs in Lactobacillus casei-Pediococcus group of lactic acid bacteria using fragment analysis. FEMS Microbiol Lett. 2020;367(19). https://doi.org/10.1093/femsle/fnaa154.

45. Dar D, Sorek R. Bacterial noncoding RNAs excised from within proteincoding transcripts. mBio. 2018;9. https://doi.org/10.1128/mBio.01730-18.

46. Adams PP, Baniulyte G, Esnault C, Chegireddy K, Singh N, Monge M, et al. Regulatory roles of Escherichia coli $5^{\prime}$ UTR and ORF-internal RNAs detected by 3' end mapping. eLife. 2021;10:e62438. https://doi.org/10.7554/eLife.62438.

47. Hori T, Matsuda K, Oishi K. Probiotics: a dietary factor to modulate the gut microbiome, host immune system, and gut-brain interaction. Microorganisms. 2020;8(9). https://doi.org/10.3390/microorganisms8091401.

48. Holmqvist E, Wagner EGH. Impact of bacterial sRNAs in stress responses. Biochem Soc Trans. 2017;45(6):1203-12. https://doi.org/10.1042/BST20160363.

49. Mikutis S, Gu M, Sendinc E, Hazemi ME, Kiely-Collins H, Aspris D, et al. meCLICK-Seq, a substrate-hijacking and RNA degradation strategy for the study of RNA methylation. ACS Cent Sci. 2020;6(12):2196-208. https://doi. org/10.1021/acscentsci.0c01094

50. Martin M. Cutadapt removes adapter sequences from high-throughput sequencing reads. EMBnet.J. 2011;17:10-2. https://doi.org/10.14806/ej.17.1.2 00 .

51. R Core Team. R: a language and environment for statistical computing. Vienna: R Found Stat Comput; 2018

52. Smith T, Heger A, Sudbery I. UMI-tools: modeling sequencing errors in Unique Molecular Identifiers to improve quantification accuracy. Genome Res. 2017;27(3):491-9. https://doi.org/10.1101/gr.209601.116.

53. Kim D, Paggi JM, Park C, Bennett C, Salzberg SL. Graph-based genome alignment and genotyping with HISAT2 and HISAT-genotype. Nat Biotechnol. 2019;37(8):907-15. https://doi.org/10.1038/s41587-019-0201-4.

54. Liao Y, Smyth GK, Shi W. featureCounts: an efficient general purpose program for assigning sequence reads to genomic features. Bioinformatics. 2014;30(7):923-30. https://doi.org/10.1093/bioinformatics/btt656.

55. McCarthy DJ, Chen Y, Smyth GK. Differential expression analysis of multifactor RNA-Seq experiments with respect to biological variation. Nucleic Acids Res. 2012:40(10):4288-97. https://doi.org/10.1093/nar/gks042.

56. Solovyev V, Salamov A. Automatic annotation of microbial genomes and metagenomic sequences. In: Li RW, editor. Metagenomics and its applications in agriculture, biomedicine and environmental studies. New York: Nova Science Publisher; 2011. p. 61-78.

57. Altschul SF, Gish W, Miller W, Myers EW, Lipman DJ. Basic local alignment search tool. J Mol Biol. 1990;215(3):403-10. https://doi.org/10.1016/S0022-2 836(05)80360-2.

58. Rice P, Longden I, Bleasby A. EMBOSS: the European Molecular Biology Open Software Suite. Trends Genet. 2000;16(6):276-7. https://doi.org/10.101 6/S0168-9525(00)02024-2.

59. Madeira F, Mi PY, Lee J, Buso N, Gur T, Madhusoodanan N, et al. The EMBLEBI search and sequence analysis tools APIs in 2019. Nucleic Acids Res. 2019:47(W1):W636-41. https://doi.org/10.1093/nar/gkz268.

60. Lorenz R, Bernhart SH, Höner zu Siederdissen C, Tafer H, Flamm C, Stadler PF, et al. ViennaRNA Package 2.0. Algorithms Mol Biol. 2011;6(1):26. https:// doi.org/10.1186/1748-7188-6-26.

61. Thorvaldsdóttir H, Robinson JT, Mesirov JP. Integrative Genomics Viewer (IGV): high-performance genomics data visualization and exploration. Brief Bioinform. 2013;14(2):178-92. https://doi.org/10.1093/bib/bbs017.

62. Hammer O, Harper D, Ryan P. PAST: Paleontological Statistics Software Package for Education and Data Analysis. Palaeontol Electron. 2001;4:1-9.

\section{Publisher's Note}

Springer Nature remains neutral with regard to jurisdictional claims in published maps and institutional affiliations.

Ready to submit your research? Choose BMC and benefit from:

- fast, convenient online submission

- thorough peer review by experienced researchers in your field

- rapid publication on acceptance

- support for research data, including large and complex data types

- gold Open Access which fosters wider collaboration and increased citations

- maximum visibility for your research: over $100 \mathrm{M}$ website views per year

At $\mathrm{BMC}$, research is always in progress.

Learn more biomedcentral.com/submissions 